\title{
Comprehensive Assessment of the Effect of Urban Built-Up Land Expansion and Climate Change on Net Primary Productivity
}

\author{
Pengyan Zhang, ${ }^{1,2}$ Yanyan Li, ${ }^{1}$ Wenlong Jing $\mathbb{D}^{\circ},{ }^{3}$ Dan Yang, ${ }^{1}$ Yu Zhang, ${ }^{1}$ Ying Liu, ${ }^{1}$ \\ Wenliang Geng, ${ }^{1}$ Tianqi Rong, ${ }^{1}$ Jingwen Shao, ${ }^{1}$ Jiaxin Yang, ${ }^{1}$ and Mingzhou Qin $\mathbb{D}^{1,2}$ \\ ${ }^{1}$ Key Laboratory of Geospatial Technology for Middle and Lower Yellow River Region, \\ Research Center of Regional Development and Planning, Institute of Agriculture and Rural Sustainable Development, \\ Henan Overseas Expertise Introduction Center for Discipline Innovation (Ecological Protection and Rural Revitalization Along \\ the Yellow River), Henan University, Kaifeng 475004, China \\ ${ }^{2}$ Collaborative Innovation Center on Yellow River Civilization of Henan Province, Henan University, Kaifeng 475001, China \\ ${ }^{3}$ Key Laboratory of Guang dong for Utilization of Remote Sensing and Geographical Information System, \\ Guang dong Open Laboratory of Geospatial Information Technology and Application, Guangzhou Institute of Geography, \\ Guangzhou, China
}

Correspondence should be addressed to Wenlong Jing; jingwl@lreis.ac.cn and Mingzhou Qin; mzqin@henu.edu.cn

Received 11 February 2020; Revised 17 March 2020; Accepted 23 March 2020; Published 5 May 2020

Guest Editor: Jun Yang

Copyright (c) 2020 Pengyan Zhang et al. This is an open access article distributed under the Creative Commons Attribution License, which permits unrestricted use, distribution, and reproduction in any medium, provided the original work is properly cited.

\begin{abstract}
Urbanization is causing profound changes in ecosystem functions at local and regional scales. The net primary productivity (NPP) is an important indicator of global change, rapid urbanization and climate change will have a significant impact on NPP, and urban expansion and climate change in different regions have different impacts on NPP, especially in densely populated areas. However, to date, efforts to quantify urban expansion and climate change have been limited, and the impact of long-term continuous changes in NPP has not been well understood. Based on land use data, night light data, NPP data, climate data, and a series of social and economic data, we performed a comprehensive analysis of land use change in terms of type and intensity and explored the pattern of urban expansion and its relationship with NPP and climate change for the period of 2000-2015, taking Zhengzhou, China, as an example. The results show that the major form of land use change was cropland to built-up land during the 2000-2015 period, with a total area of $367.51 \mathrm{~km}^{2}$ converted. The NPP exhibited a generally increasing trend in the study area except for built-up land and water area. The average correlation coefficients between temperature and NPP and precipitation and NPP were 0.267 and 0.020 , respectively, indicating that an increase in temperature and precipitation can promote NPP despite significant spatial differences. During the examined period, most expansion areas exhibited an increasing NPP trend, indicating that the influence of urban expansion on NPP is mainly characterized by an evident influence of the expansion area. The study can provide a reference for Zhengzhou and even the world's practical research to improve land use efficiency, increase agricultural productivity and natural carbon sinks, and maintain low-carbon development.
\end{abstract}

\section{Introduction}

As an important part of the global carbon cycle, the terrestrial biosphere is affected by urban expansion and climate change [1-3]. The trend of global terrestrial net primary productivity (NPP) is still uncertain [4]. In the context of climate change, the threat of rapid global urbanization to terrestrial ecosystem productivity, environment, livelihoods, and food security has gradually become one of the most critical issues in the world $[5,6]$. The net primary productivity refers to the amount of organic matter accumulated by green plants in unit time per unit area $[7,8]$. It is an important indicator in the determination of the carbon source, carbon sink health, and sustainable development of ecosystems and is the main factor regulating ecological processes. It also helps in assessing the carrying capacity of 
ecosystems [9-11]. Terrestrial vegetation provides a great deal of food, fuel, and building materials for human beings; therefore, in the context of global change, more and more researchers are beginning to pay attention to the trend of NPP in terrestrial ecosystems [12].

With the rapid growth in the world economy, urbanization is increasing. Urbanization is a complex process involving population transfer, land use change, urban function change, and urban form $[13,14]$. Urbanizationinduced changes may have a significant impact on the ground and thus affect the structure and function of ecosystems, as well as regional climates [15-17]. Therefore, studying the response of NPP to urban expansion and climate change can provide a better understanding of the function of ecosystems, which is important for balancing the relationship between development and environment and for the rational use of natural resources [18-20]. The NPP is an important ecological indicator for judging sustainable development and can help assess the carbon budget of terrestrial ecosystems $[9,21,22]$. The NPP has been widely used to monitor the state of carbon cycles in regions of different sizes [23-25]. Changes in NPP over a specific period can help quantify vegetation growth, which is related to the amount of vegetation and the environment in which it grows. Different models have been used to enrich the research results provided by NPP trends, primarily at a global level [26, 27], at a national level [28], and in ecosensitive areas [22, 29]. By comparing annual and seasonal NPP estimates from 15 global models in latitude zones and biomes, Cramer et al. [26] found that NPP estimates vary over time and space. Most previous research studies have been conducted at the global, national, or other macrolevels; studies at the city level are limited. The impact of urbanization on terrestrial ecosystems has been assessed based on the NPP indicator [30-32]. In addition, model estimation is a convenient method for determining NPP, as field measurements require significant human and material resources and data on urban areas, which are difficult to obtain. With the development of remote sensing technology, the surface information of any region can be comprehensively and continuously obtained $[26,33]$. To analyze the impact of urban expansion on NPP in the past few decades, a longterm NPP time series with a high time resolution is required. The spatial distribution of NPP in urban areas can be determined using data from the moderate resolution imaging spectroradiometer (MODIS), with proven accuracy. The spatial changes in NPP in urban areas can thus be better reflected.

The response of NPP to urban expansion and the factors influencing NPP have been widely studied [34, 35]. Most studies have shown that urban landscape and land use changes lead to carbon loss [36] and that land use changes have a negative impact on urban NPP [37]. However, these studies employed two time nodes when quantifying the impact of land use change on NPP and only few studied the spatialization of land expansion by urbanization and the impact of land expansion on NPP from a time and space perspective. Several scholars have relied on DMSP/OLS night light data to carry out a wide range of spatial research, such as those on population migration [38], anthropogenic carbon emissions [39, 40], and night lighting data particularly for determining built-up land and other aspects for a wide range of applications [41, 42], with good results. However, these studies were limited to the time period from 1992 to 2013; only few scholars have connected MODIS and NPP-VIIRS (Visible Infrared Imaging Radiometer Suite (VIIRS) onboard the Suomi National Polar-Orbiting Partnership (Suomi NPP) spacecraft) to simulate urban expansion [43]. Appropriate time series updates are thus required. The factors influencing NPP include land use change, vegetation, climate, and topography. Although the factors influencing NPP have been widely studied, particularly the correlation between NPP and climate factors, the studies have primarily focused on a single dynamic change perspective. In other words, the correlation between climate change and NPP change was analyzed by establishing a relationship between them, with few comprehensive studies on the impact of land expansion combined with climate factors on NPP. Therefore, quantifying the impact of human activities and climate change on NPP is an important step in formulating sustainable development of urban ecosystems in the context of climate change and human activities.

Henan province is located in central China, has a temperate continental climate, and is suitable for multicrop growth. This province is known for its agriculture, grain, and population. Zhengzhou is the capital of Henan province and is China's national center. In recent years, with the change in national policies, urbanization and industrialization have been taking place at a rapid rate, leading to an increase in the number of urban areas and population explosion. The urban landscape in Zhengzhou has undergone rapid changes, which has affected the local ecological environment. In this study, we used relevant data to analyze the response of NPP to urban expansion and climate change in Zhengzhou during the period of 2000-2015. We provide a reference for urban land use and ecological environment development in the regional centers of developing and agricultural countries. This study can fill the gaps discussed above, including broadening the time series of night lighting data, innovatively combining two kinds of night lighting data to simulate the change of urban construction land, and comprehensive studies on the impact of land expansion combined with climate factors on NPP. Strong data and new method will enhance the accuracy compare with previous studies. Detailed contents of this research include the following: (1) analysis of land use type changes and NPP changes; (2) analysis of the relationships between NPP and climate factors; (3) analysis of changes in land use intensity and urban built-up area; (4) exploration of the impact of urban built-up land on NPP change.

\section{Materials and Methods}

2.1. Study Area. Zhengzhou is the capital of Henan province, bordering the Yellow River in the north (Figure 1). It is located at $112^{\circ} 42^{\prime}-114^{\circ} 14^{\prime} \mathrm{E}$ and $34^{\circ} 16^{\prime}-34^{\circ} 58^{\prime} \mathrm{N}$. The region has a warm temperate continental climate, with an annual precipitation of approximately $639.2 \mathrm{~mm}$ and an average 


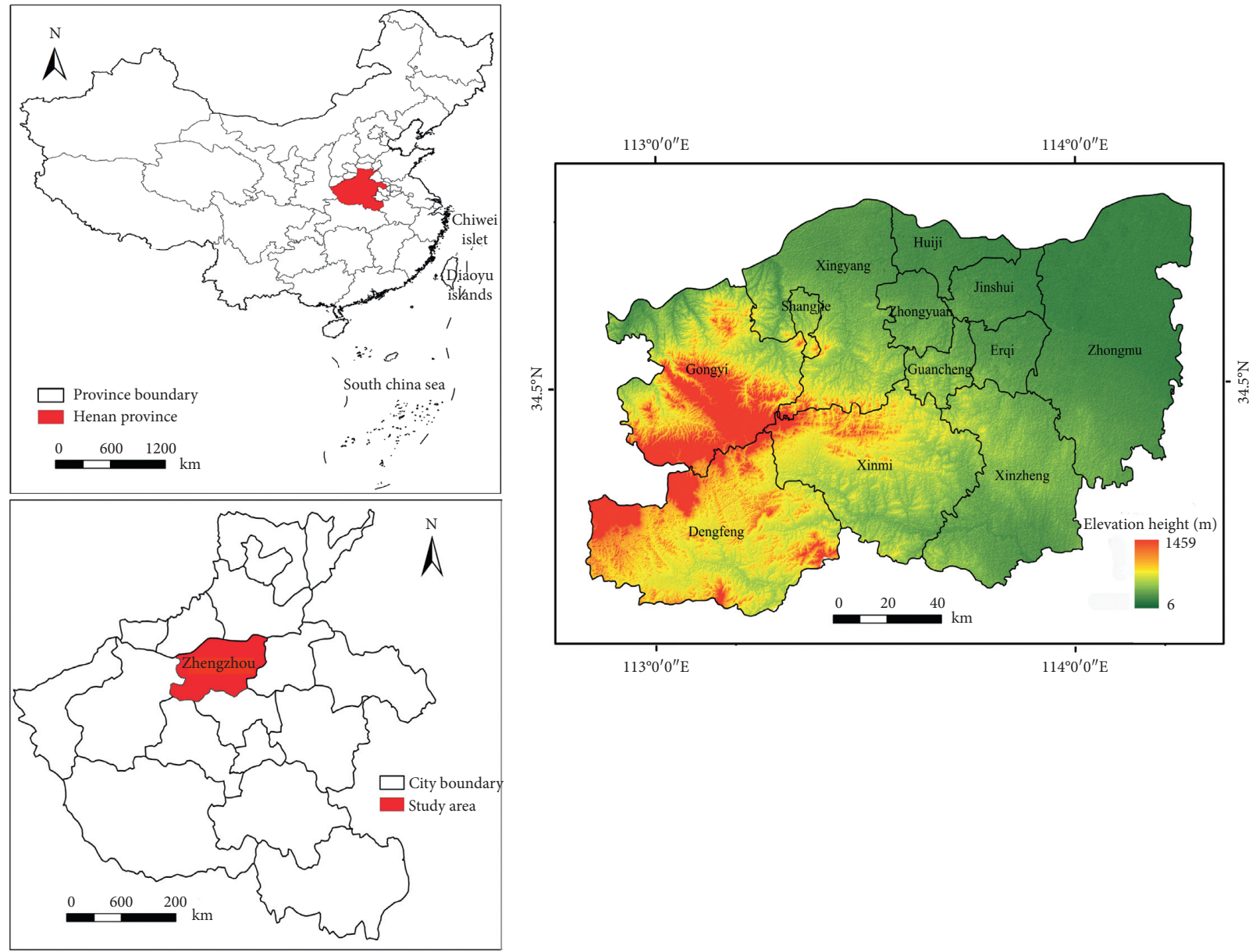

Figure 1: The location of study area.

annual temperature of $14.2^{\circ} \mathrm{C}$. The dominant striped vegetation is the temperate deciduous evergreen mixed broadleaved forest belt, and the distribution of the flora is in the middle north temperate zone and east Asia. By 2018, Zhengzhou had a total area of $7446 \mathrm{~km}^{2}$, a built-up land area of $830.97 \mathrm{~km}^{2}$, a total population of 101.36 million, and a total GDP of 101.433 billion yuan. In recent years, due to policy guidance, urbanization in Zhengzhou has been accelerating, and the urbanization rate in 2018 reached the top of the national rate of growth, at $1.59 \%$. This rapid urbanization process is accompanied by several urban land development projects; land use change is thus inevitable.

2.2. Data Sources. The datasets used in this study and data preprocessing conducted are as follows:

(1) The land use data for 2000, 2005, 2010, and 2015 in period of 2000-2015 were derived from the Resource and Environment Data Center of the Chinese Academy of Sciences (http://www.resdc.cn/). The socioeconomic data were derived from the statistical yearbook of Henan Province and Zhengzhou City (Henan statistics bureau Henan general team of investigation under the NBS, 2001-2016; Zhengzhou statistics bureau Zhengzhou general team of investigation under the NBS, 2001-2016). The climate data between 2000 and 2015 in Zhengzhou was extracted from the whole 745 meteorological stations, which were obtained from the China meteorological data network (http://data.cma.gov.cn/).

(2) The MODIS NPP data for the period of 2000-2015 were downloaded from the Numerical Terradynamic Simulation Group (NTSG) of the University of Montana (http://www.ntsg.umt.edu/). In general, the accuracy of MODIS NPP estimates has been proven to be consistent with the NPP observed onsite [44]. The dataset is in TIF format with a resolution of $30 \operatorname{arcsec}$ (approximately $1 \mathrm{~km}$ ). We extracted the Chinese NPP from the global map and excluded nonvegetation areas.

(3) Night lighting data for the period of 2000-2015 and DMSP-OLS night stable light (NSL) data for the period of 2000-2013 were obtained from NASA's (http://ladsweb.nascom.nasa.gov) data archiving and distribution system. The stable light data include lights from cities, towns, and other places with 
persistent light sources, with the background noise eliminated. The NPP-VIIRS NSL data for the period of 2014-2015 were obtained from the National Environmental Information Center website (https:// www.ngdc.noaa.gov). Prior to data processing, the monthly average data of 2014 and 2015 from January to December were combined into annual data through ENVI 5.1. NPP-VIIRS NSL data processing included noise cancellation and continuity correction of OLS night light data using DMSP-OLS.

First, the DMSP-OLS night light data of 2013 were extracted as a dark background mask, and the mask was then used to remove unexpected noise from the NPP-VIIRS night lighting data for 2014 and 2015.

Second, according to Li et al. [45], the average light value $(\mathrm{DN})$ of the NPP-VIIRS night light data is exponentially correlated with the DN value of DMSP-OLS night light data. Accordingly, we can obtain the corrected NPP-VIIRS night light data. The formula is as follows:

$$
Y=a * X_{b} .
$$

After further processing, equation (1) can be converted to the following:

$$
X=e^{((\ln Y-\ln a) / b)} .
$$

Here, $Y$ represents the DN value of DMSP-OLS night light data, $X$ represents the DN value of NPP-VIIRS night light data, and $a$ and $b$ are coefficients.

(4) The temperature and precipitation data in the 2000-2015 time series were derived from the Resource Environmental Science Data Center of the Chinese Academy of Sciences (http://www.resdc.cn/doi/doi.aspx?doiid=32).

\subsection{Methods}

2.3.1. NPP Trend Analysis. The trend of change in NPP at the cell level is analyzed and predicted using a one-way linear regression analysis, and the formula is as follows:

$$
\text { Slope }=\frac{n \times \sum_{i=1}^{n} i \times \mathrm{NPP}_{i}-\sum_{i=1}^{n} i \sum_{i=1}^{n} \mathrm{NPP}_{i}}{n \times \sum_{i=1}^{n} i^{2}-\left(\sum_{i=1}^{n} i^{2}\right)} .
$$

Here, $n$ represents the number of years $(n=16), \mathrm{NPP}_{i}$ is the NPP for year $i(i=1,2,3, \ldots, 16)$, and slope is the slope for the NPP at the individual cell level of the slope. If the slope $>0$, an increasing trend is indicated; the greater the value, the more evident the increasing trend. If the slope $<0$, a decreasing trend is indicated; the lower the value, the more evident the decreasing trend.

2.3.2. Correlation Analysis. The trend of change in NPP and the temperature and precipitation correlation coefficient on the space-time scale can be calculated using the Pearson correlation coefficient method. The correlation coefficient $\left(R_{x y}\right)$ is calculated as follows:

$$
R_{x y}=\frac{\sum_{i=1}^{n}\left[\left(x_{i j}-\bar{x}_{j}\right)\left(y_{i j}-\bar{y}_{j}\right)\right]}{\sqrt{\sum_{i=1}^{n}\left(x_{i j}-\bar{x}_{j}\right)^{2} \sum_{i=1}^{n}\left(y_{i j}-\bar{y}_{j}\right)^{2}}} .
$$

Here, $n$ is the year serial number, $x_{i j}$ is the value of the NPP in the first year of the $j$ cell, and $x_{j}$ is the average of the NPP $j$ cell over 16 years, i.e., from 2000 to 2015 . Similarly, $y_{i j}$ is the value of the first $j$ cell of temperature or precipitation, and $y_{j}$ is the average of the first $j$ cell of temperature or precipitation over the 16 years of 2000-2015. To check the validity of the model, a $p$-test was used, and the tendencies were classified into 3 categories: highly significant, significant, and no significant change.

2.3.3. Urban Built-Up Land Expansion Simulation. It is of great significance to understand the spatial expansion trend of urban built-up land for guiding the rational expansion of urban land [46-51]. Night light data is a common kind of remote sensing data analyzing the city scale [52-54]. The average night light data constitute a cloudless composite map generated by the $\mathrm{DN}$ value for each time period, with a spatial resolution of $1 \mathrm{~km}$. The night lighting data from DMSP-OLS provides a tool for monitoring urban sprawl from time and space perspectives $[55,56]$. The city area is determined by the threshold of the DN. If the DN of the region is greater than the threshold, the region is defined as a city. Different scenarios for the total urban area are obtained by changing the threshold of $\mathrm{DN}$. When the simulated total urban areas are close to each other, the threshold of DN is noted in the urban land use census data and applied to the process of measuring urban expansion. The recorded nighttime light image data were used as an indicator of urban expansion.

2.3.4. Land Use Intensity. In recent years, Zhengzhou has experienced rapid urbanization, with a significant growth in economic development, leading to an increase in population and resource consumption. The land use intensity has changed dramatically. In this study, seven indicators were selected to measure the change in land use intensity: urban population, GDP, industrial output, agricultural output, fixed asset input, quantity of shipments, and electricity consumption.

\section{Results}

3.1. Changes in Land Use Types. To determine the land use change in Zhengzhou during the period of 2000-2015, the land use transfer matrix for the period was obtained (Table 1). Table 1 shows that the transfer of cropland to built-up land is the main form of land use transfer; the area is approximately $367.51 \mathrm{~km}^{2}$, accounting for approximately $51.08 \%$ of the total land use transfer area. Water area is the second largest type of land occupied by cropland in addition 
TABLE 1: Land transfer matrix between 2000 and $2015\left(\mathrm{~km}^{2}\right)$.

\begin{tabular}{|c|c|c|c|c|c|c|c|}
\hline \multirow{2}{*}{2000} & \multicolumn{7}{|c|}{2015} \\
\hline & Cropland & Forest & Grassland & Water area & Built-up land & Unused land & Total \\
\hline Cropland & 4475.95 & 30.89 & 33.07 & 103.77 & 367.51 & 0.14 & 5011.32 \\
\hline Forest & 32.37 & 709.01 & 9.20 & 1.89 & 11.27 & 0.16 & 763.89 \\
\hline Grassland & 31.52 & 11.08 & 645.12 & 1.36 & 3.32 & 0.00 & 692.39 \\
\hline Water area & 19.99 & 2.06 & 0.47 & 166.54 & 11.69 & 0.00 & 200.76 \\
\hline Built-up land & 43.28 & 0.89 & 0.87 & 1.84 & 801.72 & 0.03 & 848.62 \\
\hline Unused land & 0.09 & 0.15 & 0.05 & 0.10 & 0.43 & 2.61 & 3.42 \\
\hline Total & 4603.19 & 754.06 & 688.77 & 275.50 & 1195.94 & 2.94 & 7520.41 \\
\hline
\end{tabular}

to built-up land, with an area of approximately $103.77 \mathrm{~km}^{2}$; the water area increases significantly. Cropland is not only the main type of land transfer out but also the main land receiver, with grassland and built-up land being transferred to areas of $32.37 \mathrm{~km}^{2}, \quad 31.52 \mathrm{~km}^{2}$, and $43.28 \mathrm{~km}^{2}$, respectively.

Figures 2(a) and 2(b) show the spatial distributions of the type of unchanged land and the type of transferred land in Zhengzhou City during the period of 2000-2015. Figure 2(a) shows that cropland was the main land use type in Zhengzhou and was spread throughout the region. The builtup land was concentrated in the central and northern regions in the form of small patches scattered in some parts. Ecological land was mainly distributed in the western part of the region in the form of large patches, and the water area was mainly distributed at the borders of the city in the northern area in the form of a ribbon. According to the land transfer situation (Figure 2(b)), eight land use types were selected in the order from highest to lowest use to show the spatial distribution of land use transfer; the total area of the eight land transfer types accounted for $92.07 \%$ of the total area of the land transfer. Among them, the transfer from cropland to built-up land was mainly distributed in the central urban area, as a result of urban land expansion. The transfer from cropland to water area was mainly distributed around the land along the waters.

3.2. Changes in NPP of 2000-2015. Figure 3(a) shows that the NPP in general was distributed in areas other than the builtup land and water area, showing a generally increasing trend. Among them, the low value of NPP was mainly distributed in the eastern, southwestern, and southern border areas of Zhengzhou City in the form of small patches, and the areas with a high NPP value were mainly distributed throughout the city in the form of large patches. As shown in Figure 3(b), the value of the NPP slope ranges from negative to positive; the slope value represents the change in NPP itself in the period of 2000-2015. The positive values indicate an increasing trend in NPP, whereas negative values indicate a decreasing trend in NPP. The NPP growth area was mainly concentrated in the southern and northwestern regions of Zhengzhou, wherein the growth trend was stronger in some parts of central southern area. The NPP with a downward trend was mainly distributed in the areas surrounding the development of built-up land, which were concentrated in the northern and northeastern regions of Zhengzhou City. The average slope of the NPP trend of 2000-2015 was 0.55, indicating that the NPP value in Zhengzhou showed an overall increasing trend.

3.3. Relationships between NPP and Climate Factors. Based on the relevant analysis, the correlation coefficient map of precipitation, temperature, and NPP was obtained, as shown in Figures 4(a) and 4(b). The p-value tests indicated that only a small percentage of the areas passed the $p>0.05$ significance test for both negative and positive correlations of both precipitation and temperature (Figures 3(c) and 3(d)). Overall, the average phase relationship values $(R)$ of precipitation and temperature are 0.267 and 0.020 , respectively. Figure $4(\mathrm{a})$ shows the distribution of the coefficient $R$ between precipitation and NPP for the period of 2000-2015, in which positive values account for $96.38 \%$ and negative values account for $3.62 \%$. The positive coefficient indicates that precipitation has a positive correlation with NPP, that is, the increase in precipitation can promote the growth of NPP to some extent. The positive values were observed in most parts of the city in the form of large patches, wherein the high values of the positive coefficient were mainly observed in the central and northwest regions. The negative values, which represent a negative correlation between precipitation and NPP values, were primarily observed throughout the region in the form of small patches. Figure 4(b) shows the distribution of the correlation coefficient between temperature and NPP for the period of $2000-2015$, with positive values accounting for $56.57 \%$ and negative values accounting for $43.43 \%$. The positive values indicate a positive correlation between temperature and $\mathrm{NPP}$, that is, an increase in temperature promotes the increase of NPP to a certain extent. The positive values are observed mainly in the form of small patches in most areas of the whole region, with higher positive values concentrated in the eastern and central areas. The negative values indicate a negative correlation between temperature and NPP, that is, an increase in temperature will inhibit the growth of NPP to a certain extent. They are primarily observed in the western and northwest areas in the form of small patches and in the form of large plaques that are densely distributed in the central and central northern areas. 


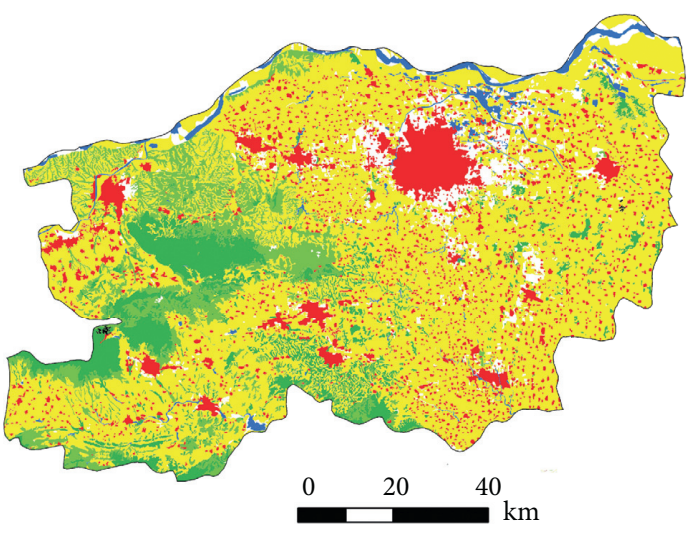

$\begin{array}{ll}\text { Cropland } & \square \text { Water area } \\ \text { Forest } & \square \text { Built-up land } \\ \text { Grassland } & \text { Unused land }\end{array}$

(a)
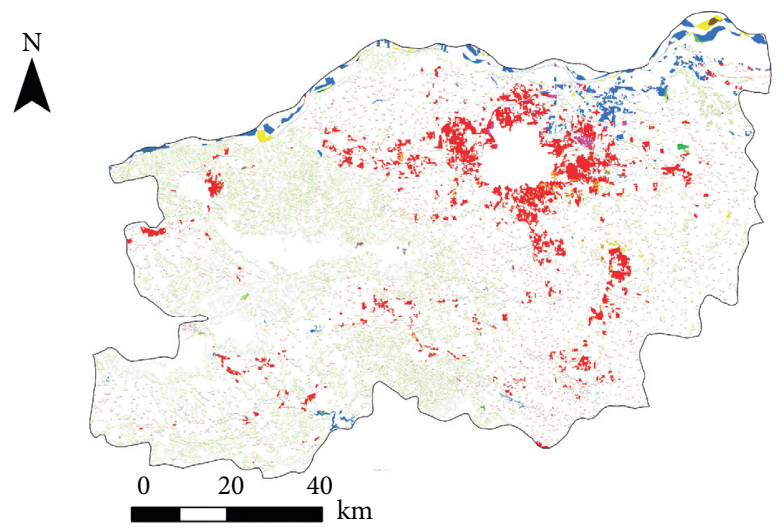

$\stackrel{N}{\Lambda}$

FIGURE 2: Spatial distribution of land without changes in land use type (a) and transferred land (b).

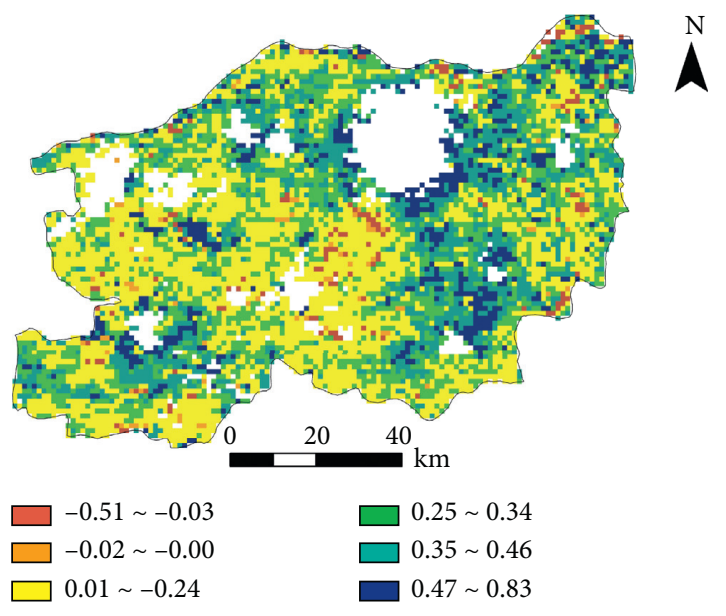

(a)

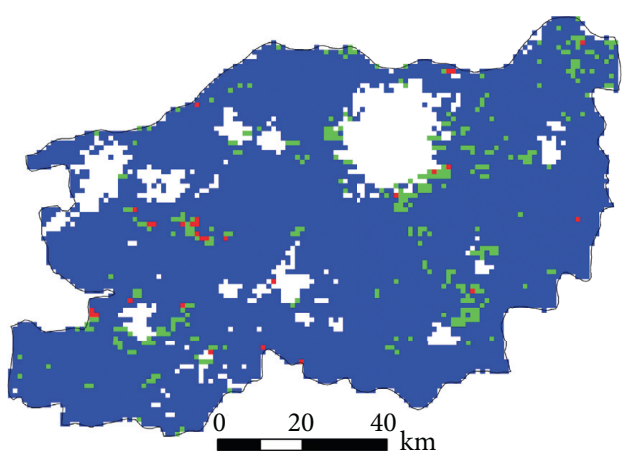

$\square$ Highly significant

$\square$ Significant

- Nonsignificant
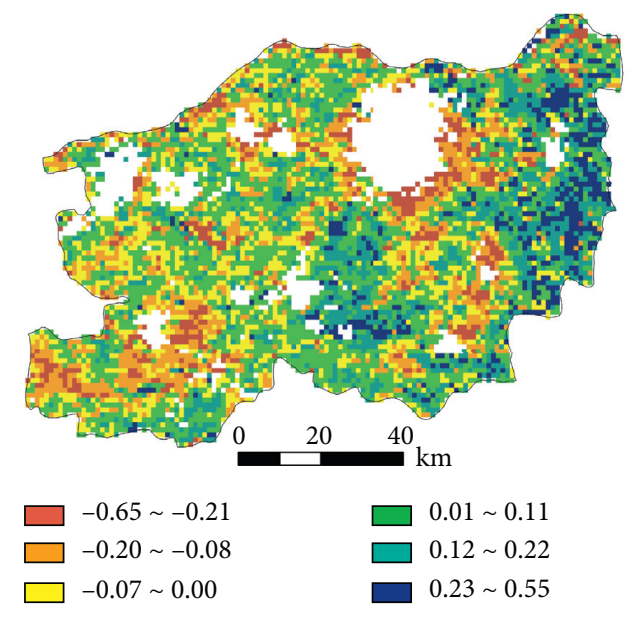

$\square-0.65 \sim-0.21$
$-0.20 \sim-0.08$
$\square-0.07 \sim 0.00$

$\square .01 \sim 0.11$
$\square 0.12 \sim 0.22$
$\square 0.23 \sim 0.55$

(b)

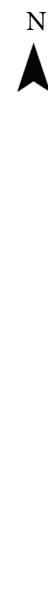

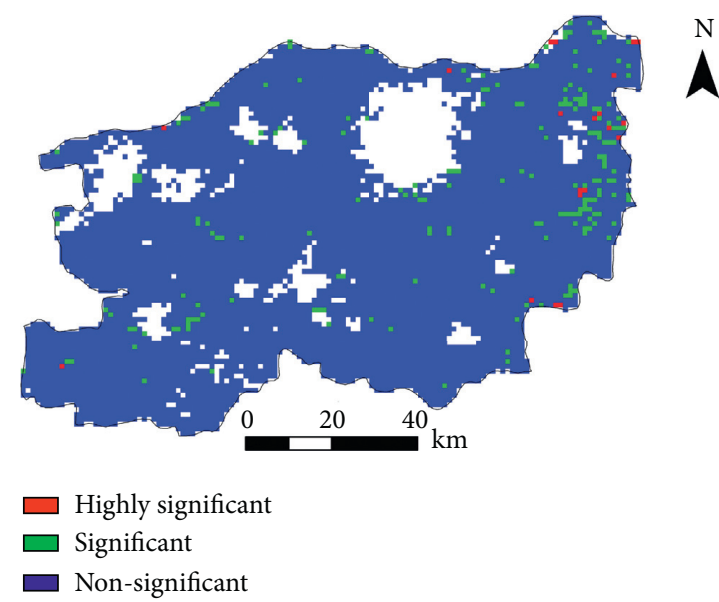

(d)

Figure 3: Correlation coefficients and significance tests between $(a, c)$ NPP and precipitation and (b, d) NDVI and temperature. Highly significant, significant $(+)$, and nonsignificant areas are shown in (c) and (d), where the positive correlations between NDVI and precipitation and temperature are significant at the $99 \%$ and $95 \%$ confidence levels, and the nonsignificant positive and negative correlations. 


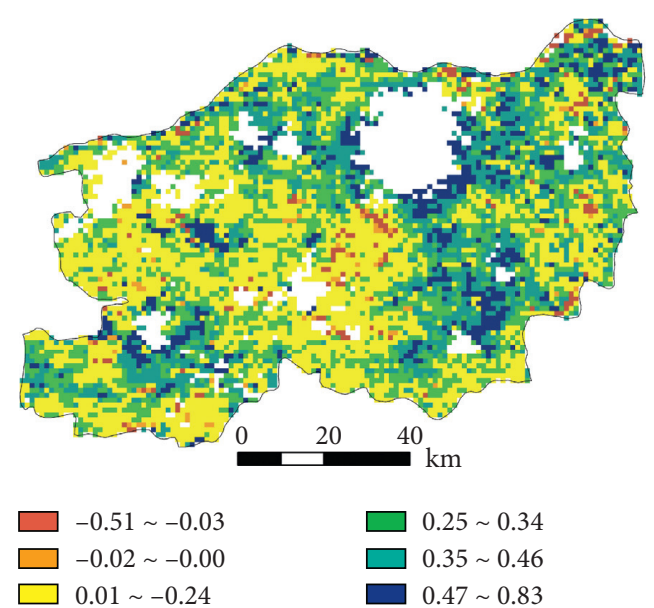

(a)
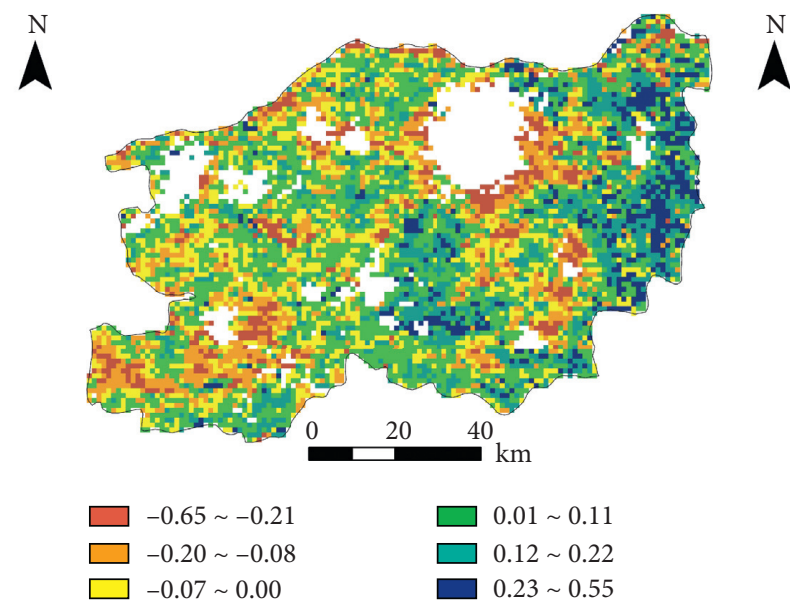

(b)

FIGURE 4: Spatial distribution of the correlation coefficients between NPP and precipitation (a) and temperature (b).

3.4. Change in Land Use Intensity and Urban Built-Up Area. Land use intensity can reflect the rates of energy emissions and socioeconomic development to a certain extent, and it has been documented that socioeconomic development indicators can be a good indicator of land use intensity $[57,58]$. We selected seven main indicators to reflect the land use intensity of Zhengzhou City and calculated the ratio between typical years to analyze the changing trends (Table 2). According to Table 2, the total population increased steadily from 2000 to 2015, but the growth amount was greater, and the growth rate showed a steady downward trend. The increase in GDP was most pronounced, increasing from 73.802 billion yuan to 731.152 billion yuan. Both industrial output and agricultural output increased significantly, particularly in ratios of $2.99 \%$ and $1.75 \%$, respectively, between 2005 and 2010. From 2000 to 2015, the fixed asset investment increased from 25.839 billion yuan to 628.80 billion yuan, and the increase during the period of 2005-2010 was the highest compared with the changes during different time periods. The quantity shipped increased significantly overall, from $15,781.00$ million tons to $24,639.00$ million tons, but decreased during the period of $2005-2010$ by a ratio of 0.87 .

Figure 5 show the distribution of urban built-up land in the typical years ranging from 2000 to 2015 in Zhengzhou. From a spatial point of view, the urban built-up land was mainly distributed in the central and northern parts of the city, which are the most developed parts of the urban economy. Urban built-up land expanded around the northern part of the city during the period of 2000-2015, and the area of urban built-up land increased gradually, with the fastest growth reported in the period of 2010-2015.

\subsection{Impact of Urban Built-Up Land on NPP Change.} Figure 6 shows the relationship between NPP and urban built-up land expansion. The correlation between NPP and urban built-up land expansion was relatively strong, with more areas showing a positive correlation. The areas with negative NPP value were mainly distributed in the expansion area of the central city, indicating that the expansion of urban built-up land inhibits the NPP. The areas with positive values were distributed in most parts of the region, indicating that the impact of urban expansion on NPP is mainly concentrated in the expansion areas.

\section{Discussion}

The rapid expansion of urban areas has significantly affected regional ecosystems, making it extremely important to quantify the impact of urban expansion and climate change on NPP. Using land use data, night light data, NPP data, climate data, and a series of socioeconomic data, we explored the expansion of urban built-up land in Zhengzhou City during the period of 2000-2015 and the response of NPP to urban expansion and climate change. The study provides a reference for land managers to formulate land policies towards low carbon and sustainable development.

Built-up land expansion is the main form of land use change in Zhengzhou and is quite common in China, as the country is undergoing rapid urbanization. However, the land use changes in China and those in Europe $[59,60]$, the United States [61], Australia [62], and other developed countries that have completed the process of urbanization are different. As Zhengzhou is located in the region with a general population and economic level, cropland and ecological land are the main land use types, and land use transformation is more characteristic, compared with the northwest, inland areas, and other underdeveloped areas of China. Cropland being occupied by built-up land is the main change in land use types that occurs in Zhengzhou, which is mainly due to the social and economic development. This result is consistent with previous studies on land use change [63, 64]. From 2000 to 2015, the population increased to 9.569 million, and the urbanization rate in Zhengzhou increased from $55.1 \%$ to $69.7 \%$. To accommodate more urban 
TABLE 2: Change in land use intensity index in Zhengzhou during the period of 2000-2015.

\begin{tabular}{lccccccc}
\hline & $\begin{array}{c}\text { Urban } \\
\text { population/10,000 }\end{array}$ & $\begin{array}{c}\text { GDP/hundred } \\
\text { million }\end{array}$ & $\begin{array}{c}\text { Industrial } \\
\text { output/ } \\
\text { hundred } \\
\text { million }\end{array}$ & $\begin{array}{c}\text { Agricultural } \\
\text { output/hundred } \\
\text { million }\end{array}$ & $\begin{array}{c}\text { Fixed } \\
\text { assets/hundred } \\
\text { million }\end{array}$ & $\begin{array}{c}\text { Quantity } \\
\text { shipped/tons }\end{array}$ & $\begin{array}{c}\text { Electricity } \\
\text { consumption/100 } \\
\text { million kWh }\end{array}$ \\
\hline 2000 & 259.11 & 738.02 & 1080.24 & 73.18 & 258.39 & 15781.00 & 78.7 \\
2005 & 424.13 & 1660.60 & 2489.33 & 126.22 & 820.00 & 23750.00 & 140.6 \\
2010 & 551.00 & 4040.89 & 7452.60 & 221.43 & 2756.98 & 20636.00 & 356 \\
2015 & 666.91 & 7311.52 & 15531.27 & 276.58 & 6288.00 & 24639.00 & 352 \\
\hline $2000-2005$ & 1.64 & 2.25 & 2.30 & 1.72 & 3.17 & 1.50 & 1.79 \\
$2005-2010$ & 1.30 & 2.43 & 2.99 & 1.75 & 3.36 & 0.87 & 1.19 \\
$2010-2015$ & 1.21 & 1.81 & 2.08 & 1.25 & 2.28 & & 0.99 \\
\hline
\end{tabular}

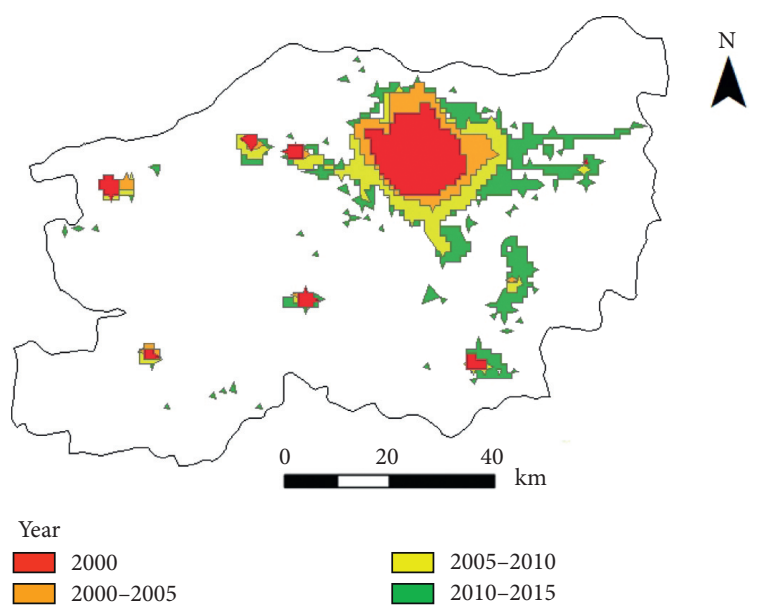

Figure 5: Urban built-up land sprawl during the period of 2000-2015, as detected using night-time light data.

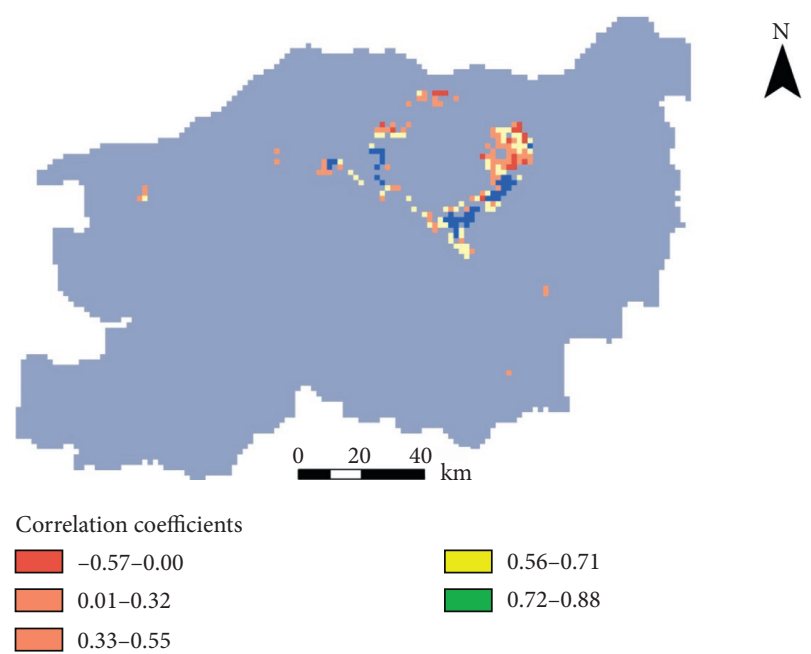

FIGURE 6: Spatial distribution of the correlation coefficients between NPP and night-time light data.

residents and under the influence of the growing real estate market [65], urban areas expanded rapidly during the study period. Although the population in rural areas has been significantly reduced, idle rural settlements are widely distributed, and land consolidation can take a long time. As cropland accounts for more than $80 \%$ of the area in Zhengzhou and is distributed in various places, the expansion of urban land requires the occupation of a large area of cropland. The spatial distribution of land transformation, shown in Figure 2, proves our conclusion that socioeconomic development is the main driving force of change in land use type. The economic level of Zhengzhou city shows a characteristic growth from center to periphery, and the land use change shows the same trend. In other words, the land circulation in the developed areas of the urban economy is more intensive.

Zhengzhou has experienced rapid urbanization in recent years, not only bringing about a growth in the economy and mass population, capital, and technology but also leading to a rapid increase in land use intensity. In this study, to represent land use intensity, we selected seven indicators, which showed a strong correlation between land use intensity and economic development level. The land use intensity gradually enhanced with the growing economy, which can be attributed to the regional differences in economic and natural resources between different periods. The differences in the economy and resources are consistent with the study conducted by Yang et al. [66], which showed that urban land use intensity increases with the increase in the level of urbanization. According to our research, the change in land use intensity has a significant effect on NPP. The areas with high land use intensity usually exhibit high levels of economic development and lower NPP values because such areas always have a large proportion of artificial vegetation and land, which can also explain the lower NPP values. In addition, areas with more natural and seminatural land use tend to have lower land use intensity [67], where cropland, forests, and grasslands account for a large proportion. With ecological land being increasingly occupied, policies and measures to promote intensive land use should be implemented to adjust land use intensity and to match the socioeconomic situation with the local condition [68]. Besides socioeconomic conditions, climate change [69], ecological conditions, and crop structures affect land use intensity to some extent.

Second, to correct and integrate the two types of night light data from different sources, we performed an exponential regression between MODIS-OLS night light data for 2013 and NPP-VIIRS night light data for 2014 and 2015 after noise processing and then obtained the revised NPP-VIIRS night light data. The reliability of this method has been verified $[39,70]$. In spatial simulations of energy-related carbon emissions, the night light data obtained from DMSPOLS and NPP-VIIRS are suitable for simulating urban land 
expansion, and there is an innovation in the integration of the two types of data and the updating of time series. The urban expansion simulated by night light data effectively reflected the land change distribution in Zhengzhou from 2000 to 2015, which also can be attributed to the economic development and urban functional planning.

Compared with previous studies, the NPP simulation performed in this study has several advantages. The NPP estimates from MODIS have been validated to be consistent with the NPP values observed in the field [44, 71]. Exist studies show that, for urban system, the MODIS NPP still has a good application $[72,73]$. As a result, the NPP simulations in previous studies have been validated, although more field observations are required for further research to improve the NPP simulation models for China (particularly in the west, where the density of field observations is low). The effects of global warming were widely demonstrated in China during the period of 2000-2015, with regions experiencing a rise in temperature accounting for $52.99 \%$ of that for the whole country. Although an increase in temperature can promote NPP to a higher extent than an increase in soil respiration, higher temperatures can also contribute to steaming and drought, leading to low vegetation productivity [74], particularly in an environment with insufficient water supply. In addition, a continuous increase in temperature will lead to increased soil respiration $[75,76]$ and decrease the NPP. Continued global warming will ultimately damage carbon sequestration in terrestrial ecosystems. Therefore, in China, reducing carbon emissions is urgently required for green, low-carbon development. Zhengzhou, which is an emerging and fast-growing city, should respond positively to the country's call for low-carbon green development. Moderate precipitation conditions are essential for vegetation growth; if the precipitation is too high or too low, vegetation growth will be affected, thus reducing NPP. For example, rainfall can increase cloud cover and thus reduce solar radiation, which is critical for vegetation growth [77]. Further water supply may create an aerobic environment in the root area, reduce soil nutrients [78], and inhibit vegetation growth. With the increase in temperature and a decrease in precipitation, ecological pressure will increase under primitive fragile environmental conditions $[79,80]$. However, rising temperatures may also cause other ecological problems, such as melting glaciers, extreme climate, and disease, which require enhanced ecological protection. Owing to extreme weather conditions, the precipitation in Zhengzhou city has been insufficient in recent years, and water resources are relatively scarce. Precipitation is a key factor for the growth of vegetation. The government should strengthen ecological protection.

For the effect of urban built-up land expansion on NPP, the impact of urban built-up land expansion on NPP may be positive or negative, depending on socioeconomic and biophysical factors $[81,82]$. The results in this study show there is negative relationship between urban built-up land and NPP at edge of the urban expansion areas, which means that the urban built-up expansion can damage the vegetation productivity in some extent. This is because with the continuous expansion of built-up land, the composition and quantity of vegetation decreased, then the net primary productivity of vegetation will decrease, which is consistent with the existing study [83]. While on the other areas, the relationships between urban built-up land and NPP are positive on the whole. The negative impact of urban expansion on NPP will disturb carbon balance to some extent. In addition, in Zhengzhou, human activities, such as desertification, loss of agricultural use, and deforestation, hamper green development; most of these activities may also disrupt the carbon balance. Therefore, government departments should take effective environmental protection measures to strictly prohibit such activities.

\section{Conclusions}

Unlike previous studies, this study first simulated urban expansion from night light data by integrating the night light data obtained from DMSP-OLS and NPP-VIIRS and explored the response of NPP to urban expansion and climate change. This study can serve as a reference for urban green development.

We found that cropland is the main land use type in Zhengzhou City, and from 2000 to 2015, the land transfer of cropland to built-up land was the main pattern of land use change, with a total area of $367.51 \mathrm{~km}^{2}$ being converted; this was common in most cities of China. Areas other than the built-up land and water area exhibited a generally increasing NPP trend; these areas were mainly distributed in the southern and northwest regions of Zhengzhou. Areas around the development of built-up land exhibited a downward trending NPP. Both precipitation and temperature had obvious effects on NPP. The average correlation coefficients between temperature and NPP and precipitation and NPP were 0.267 and 0.020 , respectively, indicating that an increase in temperature and precipitation can promote NPP, despite significant spatial differences. Land use intensity gradually increased with economic growth. In terms of urban expansion, Zhengzhou expanded into the central city, and urban built-up expansion was mainly distributed in the central and northern parts of the city. From 2000 to 2015, most expansion areas exhibited an increasing NPP trend, indicating that the influence of urban expansion on NPP is mainly characterized by the evident influence of the expansion area.

\section{Data Availability}

The data used to support the findings of this study are available from the corresponding author upon request.

\section{Disclosure}

The funding sources had no role in the study design, data collection, analysis or interpretation, or the writing of this manuscript.

\section{Conflicts of Interest}

The authors declare that they have no conflicts of interest.

\section{Authors' Contributions}

Pengyan Zhang and Wenlong Jing designed and carried out the study. Yanyan Li, Dan Yang, and Yu Zhang participated 
in the analysis and presentation of analytic results. Ying Liu and Wenliang Geng collected and analyzed data. Tianqi Rong, Jiaxin Yang, and Jingwen Shao contributed the data used, and Mingzhou Qin revised the paper.

\section{Acknowledgments}

This study was funded by the National Natural Science Foundation of China (41601175, 41801362, and 41807066), 2018 Young Backbone Teachers Foundation from Henan Province (2018GGJS019), Program for Innovative Research Talent in the University of Henan Province (20HASTIT017), Key R\&D and Extension Projects in Henan Province in 2019 (agriculture and social development field) (192102310002), tackling of Key Scientific and Technical Project of Henan Province (202102310339), and Innovation Team Cultivation Project of The First-Class Discipline in Henan University (2018YLTD16). This study was also partly supported by the Natural Science Foundation of Guangdong Province, China (2018A030310470), GDAS's Project of Science and Technology Development (2016GDASRC-0211; 2017GDASCX0101, 0601, 0403, and 0801; 2018GDASCX-0101, 0403; 2019GDASYL-0502001, 0502001, 0301001, 0302001, 0501001, and 0401001; and 2020GDASYL20200104003), Guangdong Provincial Science and Technology Program (2018B030324001), Key Special Project for Introduced Talents Team of Southern Marine Science and Engineering Guangdong Laboratory (Guangzhou) (GML2019ZD0301), and Guangdong Innovative and Entrepreneurial Research Team Program (2016ZT06D336).

\section{References}

[1] L. R. Hutyra, B. Yoon, J. Hepinstall-Cymerman, and M. Alberti, "Carbon consequences of land cover change and expansion of urban lands: a case study in the Seattle metropolitan region," Landscape and Urban Planning, vol. 103, no. 1, pp. 83-93, 2011.

[2] L. E. Mitchell, J. C. Lin, D. R. Bowling et al., "Long-term urban carbon dioxide observations reveal spatial and temporal dynamics related to urban characteristics and growth," Proceedings of the National Academy of Sciences, vol. 115, no. 12, pp. 2912-2917, 2018.

[3] X.-P. Song, M. C. Hansen, S. V. Stehman et al., "Global land change from 1982 to 2016," Nature, vol. 560, no. 7720, pp. 639-643, 2018.

[4] X. P. Liu, F. S. Pei, Y. Y. Wen et al., "Global urban expansion offsets climate-driven increases in terrestrial net primary productivity," Nature Communications, vol. 10, no. 1, pp. 1-8, 2019.

[5] C. Nendel, Y. F. Hu, and T. Lakes, "Land-use change and land degradation on the Mongolian Plateau from 1975 to 2015-a case study from Xilingol, China," Land Degradation \& Development, vol. 29, no. 6, pp. 1595-1606, 2018.

[6] J. He, P. Zhang, W. Jing, and Y. Yan, "Spatial responses of net ecosystem productivity of the Yellow river basin under diurnal asymmetric warming," Sustainability, vol. 10, no. 10, p. 3646, 2018.

[7] C. Lorel, C. Plutzar, K.-H. Erb, and M. Mouchet, "Linking the human appropriation of net primary productivity-based indicators, input cost and high nature value to the dimensions of land-use intensity across French agricultural landscapes,"
Agriculture, Ecosystems \& Environment, vol. 283, p. 106565, 2019.

[8] M. G. De Kauwe, T. F. Keenan, B. E. Medlyn, I. C. Prentice, and C. Terrer, "Satellite based estimates underestimate the effect of $\mathrm{CO}_{2}$ fertilization on net primary productivity," Nature Climate Change, vol. 6, no. 10, pp. 892-893, 2016.

[9] S. L. Piao, J. Y. Fang, L. M. Zhou, B. Zhu, K. Tan, and S. Tao, "Changes in vegetation net primary productivity from 1982 to 1999 in China," Global Biogeochemical Cycles, vol. 19, no. 2, pp. 1605-1622, 2005.

[10] R. R. Nemani, C. D. Keeling, H. Hashimoto et al., "Climatedriven increases in global terrestrial net primary production from 1982 to 1999," Science, vol. 300, no. 5625, pp. 1560-1563, 2003.

[11] M. Khalifa, N. A. Elagib, L. Ribbe, and K. Schneider, "Spatiotemporal variations in climate, primary productivity and efficiency of water and carbon use of the land cover types in Sudan and Ethiopia," Science of the Total Environment, vol. 624, pp. 790-806, 2018.

[12] Y. Feng, J. Zhu, X. Zhao, Z. Tang, J. Zhu, and J. Fang, "Changes in the trends of vegetation net primary productivity in China between 1982 and 2015," Environmental Research Letters, vol. 14, no. 12, p. 124009, 2019.

[13] A. Guo, J. Yang, X. Xiao, J. Xia, C. Jin, and X. Li, "Influences of urban spatial form on urban heat island effects at the community level in China," Sustainable Cities and Society, vol. 53, p. 101972, 2020.

[14] X. Zhou and H. Chen, "Impact of urbanization-related land use land cover changes and urban morphology changes on the urban heat island phenomenon," Science of the Total Environment, vol. 635, pp. 1467-1476, 2018.

[15] J. Yang, Y. Wang, X. Xiao, C. Jin, J. Xia, and X. Li, "Spatial differentiation of urban wind and thermal environment in different grid sizes," Urban Climate, vol. 28, pp. 100458100513, 2019.

[16] M. M. Carreiro and C. E. Tripler, "Forest remnants along urban-rural gradients: examining their potential for global change research," Ecosystems, vol. 8, no. 5, pp. 568-582, 2005.

[17] J. W. Gregg, C. G. Jones, and T. E. Dawson, "Urbanization effects on tree growth in the vicinity of New York city," Nature, vol. 424, no. 6945, pp. 183-187, 2003.

[18] Z. Q. Gao, J. Y. Liu, M. K. Cao, K. R. Li, and B. Tao, "Impacts of land use and climate change on regional net primary productivity," Journal of Geographical Sciences, vol. 14, no. 3, pp. 581-591, 2004.

[19] L. H. Guo, C. Y. Hao, S. H. Wu, D. S. Zhao, and J. B. Gao, "Analysis of changes in net primary productivity and its susceptibility to climate change of Inner Mongolian grasslands using the CENTURY model," Geographical Research, vol. 35, no. 2, pp. 271-284, 2016.

[20] Y. Liu, Y. Yang, Q. Wang et al., "Assessing the dynamics of grassland net primary productivity in response to climate change at the global scale," Chinese Geographical Science, vol. 29, no. 5, pp. 725-740, 2019.

[21] C. Potter, S. Klooster, R. Myneni, V. Genovese, P. N. Tan, and V. Kumar, "Continental-scale comparisons of terrestrial carbon sinks estimated from satellite data and ecosystem modeling 1982-1998," Global and Planetary Change, vol. 39, no. 3-4, pp. 201-213, 2003.

[22] X. Wang, K. Tan, B. Chen, B. Z. Chen, and P. J. Du, “Assessing the spatiotemporal variation and impact factors of net primary productivity in China," Scientific Reports, vol. 7, p. 44415, 2017. 
[23] P. Ciais, M. Reichstein, N. Viovy et al., "Europe-wide reduction in primary productivity caused by the heat and drought in 2003," Nature, vol. 437, no. 7058, pp. 529-533, 2005.

[24] J. Fang, S. L. Piao, Z. Y. Tang et al., "Interannual variability in net primary production and precipitation," Science, vol. 293, no. 5536, pp. 1723a-1723, 2001.

[25] S. Piao, J. Fang, and J. He, "Variations in vegetation net primary production in the Qinghai-Xizang plateau, China, from 1982 to 1999," Climatic Change, vol. 74, no. 1-3, pp. 253-267, 2006.

[26] W. Cramer, D. W. Kicklighter, A. Bondeau et al., "Comparing global models of terrestrial net primary productivity (NPP): overview and key results," Global Change Biology, vol. 5, no. S1, pp. 1-15, 1999.

[27] R. Rafique, F. Zhao, R. de Jong, N. Zeng, and G. Asrar, "Global and regional variability and change in terrestrial ecosystems net primary production and NDVI: a model-data comparison," Remote Sensing, vol. 8, no. 3, p. 177, 2016.

[28] Q. Sun, B. Li, C. Zhou et al., "A systematic review of research studies on the estimation of net primary productivity in the three-river headwater region, China," Journal of Geographical Sciences, vol. 27, no. 2, pp. 161-182, 2017.

[29] C. R. Rollinson, Y. Liu, A. Raiho et al., "Emergent climate and $\mathrm{CO}_{2}$ sensitivities of net primary productivity in ecosystem models do not agree with empirical data in temperate forests of eastern North America," Global Change Biology, vol. 23, no. 7, pp. 2755-2767, 2017.

[30] C. He, Z. Liu, M. Xu, Q. Ma, and Y. Dou, "Urban expansion brought stress to food security in China: evidence from decreased cropland net primary productivity," Science of the Total Environment, vol. 576, pp. 660-670, 2017.

[31] J. Peng, H. Shen, W. Wu, Y. Liu, and Y. Wang, "Net primary productivity (NPP) dynamics and associated urbanization driving forces in metropolitan areas: a case study in Beijing city, China," Landscape Ecology, vol. 31, no. 5, pp. 1077-1092, 2015.

[32] S. E. Taelman, T. Schaubroeck, S. De Meester, L. Boone, and J. Dewulf, "Accounting for land use in life cycle assessment: the value of NPP as a proxy indicator to assess land use impacts on ecosystems," Science of the Total Environment, vol. 550, pp. 143-156, 2016.

[33] C. B. Field, J. T. Randerson, and C. M. Malmström, "Global net primary production: combining ecology and remote sensing," Remote Sensing of Environment, vol. 51, no. 1, pp. 74-88, 1995.

[34] C. Milesi, C. D. Elvidge, R. R. Nemani, and S. W. Running, "Assessing the impact of urban land development on net primary productivity in the southeastern United States," Remote Sensing of Environment, vol. 86, no. 3, pp. 401-410, 2003.

[35] S. Wu, S. Zhou, D. Chen, Z. Wei, L. Dai, and X. Li, "Determining the contributions of urbanisation and climate change to NPP variations over the last decade in the Yangtze river delta, China," Science of the Total Environment, vol. 472, pp. 397-406, 2014.

[36] D. Y. Yu, H. B. Shao, P. J. Shi, W. Q. Zhu, and Y. Z. Pan, "How does the conversion of land cover to urban use affect net primary productivity? A case study in Shenzhen city, China," Agricultural and Forest Meteorology, vol. 149, no. 11, pp. 2054-2060, 2009.

[37] F. Pei, X. Li, X. Liu, S. Wang, and Z. He, "Assessing the differences in net primary productivity between pre- and post-urban land development in China," Agricultural and Forest Meteorology, vol. 171-172, pp. 174-186, 2013.

[38] Q. Gao and K. S. M. Alimujiang, "Modeling the population spatial distribution of Tianshan north-slope urban agglomeration based on DMSP/OLS night lighting data," Northwest Population, vol. 38, no. 3, pp. 113-120, 2017.

[39] Z. Li, J. Zhong, Z. Sun, and W. Yang, "Spatial pattern of carbon sequestration and urban sustainability: analysis of land-use and carbon emission in Guang'an, China," Sustainability, vol. 9, no. 11, p. 1951, 2017.

[40] J. Ou, X. Liu, X. Li, M. Li, and W. Li, "Evaluation of NPPVIIRS nighttime light data for mapping global fossil fuel combustion $\mathrm{CO}_{2}$ emissions: a comparison with DMSP-OLS nighttime light data," PLoS One, vol. 10, no. 9, Article ID e0138310, 2015.

[41] P. J. Rayner, M. R. Raupach, M. Paget, P. Peylin, and E. Koffi, "A new global gridded data set of $\mathrm{CO}_{2}$ emissions from fossil fuel combustion: methodology and evaluation," Journal of Geophysical Research: Atmospheres, vol. 115, no. D19, pp. 111, 2010.

[42] Y. Wei, H. Liu, W. Song, B. Yu, and C. Xiu, "Normalization of time series DMSP-OLS nighttime light images for urban growth analysis with pseudo invariant features," Landscape and Urban Planning, vol. 128, no. 1, pp. 1-13, 2014.

[43] X. W. Zhang, J. S. Wu, J. Peng, and Q. W. Cao, “The uncertainty of nighttime light data in estimating carbon dioxide emissions in China: a comparison between DMSP-OLS and NPP-VIIRS," Remote Sensing, vol. 9, no. 8, p. 797, 2017.

[44] F. A. Heinsch, M. S. Maosheng Zhao, S. W. Running et al., "Evaluation of remote sensing based terrestrial productivity from MODIS using regional tower eddy flux network observations," IEEE Transactions on Geoscience and Remote Sensing, vol. 44, no. 7, pp. 1908-1925, 2006.

[45] X. Li, D. Li, H. Xu, and C. Wu, "Intercalibration between DMSP/OLS and VIIRS night-time light images to evaluate city light dynamics of Syria's major human settlement during Syrian Civil War," International Journal of Remote Sensing, vol. 38, no. 21, pp. 5934-5951, 2017.

[46] J. J. Arsanjani, M. Helbich, W. Kainz, and A. Boloorani, "Integration of logistic regression, Markov chain and cellular automata models to simulate urban expansion," International Journal of Applied Earth Observation and Geoinformation, vol. 21, pp. 265-275, 2013.

[47] B. Shu, H. Zhang, Y. Li, Y. Qu, and L. Chen, "Spatiotemporal variation analysis of driving forces of urban land spatial expansion using logistic regression: a case study of port towns in Taicang city, China," Habitat International, vol. 43, pp. 181-190, 2014.

[48] J. Yang, A. Guo, Y. Li, Y. Zhang, and X. Li, "Simulation of landscape spatial layout evolution in rural-urban fringe areas: a case study of Ganjingzi district," GIScience \& Remote Sensing, vol. 56, no. 3, pp. 388-405, 2019.

[49] J. Yang, W. L. Liu, Y. H. Li, X. M. Li, and Q. S. Ge, "Simulating intraurban land use dynamics under multiple scenarios based on fuzzy cellular automata: a case study of Jinzhou district, Dalian," Complexity, vol. 2018, Article ID 7202985, 17 pages, 2018.

[50] Y. Wang, X. Li, J. Li, Z. Huang, and R. Xiao, "Impact of rapid urbanization on vulnerability of land system from complex networks view: a methodological approach," Complexity, vol. 2018, Article ID 8561675, 18 pages, 2018.

[51] W. Chen, R. He, and Q. Wu, "A novel efficiency measure model for industrial land use based on subvector data envelope analysis and spatial analysis method," Complexity, vol. 2017, Article ID 9516267, 11 pages, 2017. 
[52] C. Small and C. D. Elvidge, "Night on earth: mapping decadal changes of anthropogenic night light in Asia," International Journal of Applied Earth Observation and Geoinformation, vol. 22, pp. 40-52, 2013.

[53] J. Song, X. Tong, L. Wang, C. Zhao, and A. V. Prishchepov, "Monitoring finer-scale population density in urban functional zones: a remote sensing data fusion approach," Landscape and Urban Planning, vol. 190, p. 103580, 2019.

[54] J. Jiang, J. Zhang, Y. Zhang, C. Zhang, and G. Tian, "Estimating nitrogen oxides emissions at city scale in China with a nightlight remote sensing model," Science of the Total Environment, vol. 544, pp. 1119-1127, 2016.

[55] Q. Zhang and K. C. Seto, "Mapping urbanization dynamics at regional and global scales using multi-temporal DMSP/OLS nighttime light data," Remote Sensing of Environment, vol. 115, no. 9, pp. 2320-2329, 2011.

[56] T. Ma, C. Zhou, T. Pei, S. Haynie, and J. Fan, "Quantitative estimation of urbanization dynamics using time series of DMSP/OLS nighttime light data: a comparative case study from China's cities," Remote Sensing of Environment, vol. 124, pp. 99-107, 2012.

[57] P. Zhang, J. He, X. Hong et al., "Carbon sources/sinks analysis of land use changes in China based on data envelopment analysis," Journal of Cleaner Production, vol. 204, pp. 702-711, 2018.

[58] T. Li, J. Li, Z. Zhou et al., "Taking climate, land use, and social economy into estimation of carbon budget in the GuanzhongTianshui economic region of China," Environmental Science and Pollution Research, vol. 24, no. 11, pp. 10466-10480, 2017.

[59] C. J. E. Schulp, C. Levers, T. Kuemmerle, K. F. Tieskens, and P. H. Verburg, "Mapping and modelling past and future land use change in Europe's cultural landscapes," Land Use Policy, vol. 80, pp. 332-344, 2019.

[60] L. Salvati, I. Zambon, F. M. Chelli, and P. Serra, "Do spatial patterns of urbanization and land consumption reflect different socioeconomic contexts in Europe?" Science of the Total Environment, vol. 625, pp. 722-730, 2018.

[61] W. Kuang, W. Chi, D. Lu, and Y. Dou, "A comparative analysis of megacity expansions in China and the U.S.: patterns, rates and driving forces," Landscape and Urban Planning, vol. 132, pp. 121-135, 2014.

[62] S. Burgin, M. J. M. Franklin, and L. Hull, "Wetland loss in the transition to urbanisation: a case study from western Sydney, Australia," Wetlands, vol. 36, no. 6, pp. 985-994, 2016.

[63] X. Fan, J. F. Li, W. X. Chen, L. J. Zhu, Q. J. Wei, and Z. S. Lin, "Spatial-temporal difference of coordinated development of county urbanization and driving factors in Henan province," Research of Soil and Water Conservation, vol. 25, no. 4, pp. 309-316, 2018.

[64] S. J. Jia, Y. Chen, R. Z. Zhang, and T. T. Pei, "Relationship among energy footprint, urban expansion and economic development in Henan province," Areal Research and Development, vol. 34, no. 1, pp. 117-122, 2015.

[65] J. Liu, W. Kuang, Z. Zhang et al., "Spatiotemporal characteristics, patterns, and causes of land-use changes in China since the late 1980s," Journal of Geographical Sciences, vol. 24, no. 2, pp. 195-210, 2014.

[66] J. Yang, G. Jin, X. Huang, K. Chen, and H. Meng, "How to measure urban land use intensity? A perspective of multiobjective decision in wuhan urban agglomeration, China," Sustainability, vol. 10, no. 11, p. 3874, 2018.

[67] F. Liu, H. M. Yan, J. Y. Liu, X. P. Xiao, and Y. W. Qin, "Spatial pattern of land use intensity in China in 2000," Acta Geographica Sinica, vol. 71, no. 7, pp. 1130-1143, 2016.
[68] D. Satterthwaite, G. McGranahan, and C. Tacoli, "Urbanization and its implications for food and farming," Philosophical Transactions of the Royal Society B: Biological Sciences, vol. 365, no. 1554, pp. 2809-2820, 2010.

[69] A. Stampfli, J. M. G. Bloor, M. Fischer, and M. Zeiter, "High land-use intensity exacerbates shifts in grassland vegetation composition after severe experimental drought," Global Change Biology, vol. 24, no. 5, pp. 2021-2034, 2018.

[70] R. Ding, "The complex network theory-based urban land-use and transport interaction studies," Complexity, vol. 2019, Article ID 4180890, 14 pages, 2019.

[71] Y. Zhang, M. Xu, H. Chen, and J. Adams, "Global pattern of NPP to GPP ratio derived from MODIS data: effects of ecosystem type, geographical location and climate," Global Ecology and Biogeography, vol. 18, no. 3, pp. 280-290, 2009.

[72] Y. Yan, X. Liu, F. Wang et al., "Assessing the impacts of urban sprawl on net primary productivity using fusion of Landsat and MODIS data," Science of The Total Environment, vol. 613614, pp. 1417-1429, 2018.

[73] Z. Qiao, L. Liu, Y. Qin, X. Xu, B. Wang, and Z. Liu, "The impact of urban renewal on land surface temperature changes: a case study in the main city of Guangzhou, China," Remote Sensing, vol. 12, no. 5, p. 794, 2020.

[74] O. Fang, Y. Wang, and X. Shao, "The effect of climate on the net primary productivity (NPP) of Pinus koraiensis in the Changbai Mountains over the past 50 years," Trees, vol. 30, no. 1, pp. 281-294, 2016.

[75] S. Chen, Y. Huang, J. Zou et al., "Interannual variability in soil respiration from terrestrial ecosystems in China and its response to climate change," Science China Earth Sciences, vol. 55, no. 12, pp. 2091-2098, 2012.

[76] B. Bond-Lamberty and A. Thomson, "Temperature-associated increases in the global soil respiration record," Nature, vol. 464, no. 7288, pp. 579-582, 2010.

[77] M. Mathur, "Functional dynamics of energy variables and their impacts on growth and population attributes of a woody perennial at arid wasteland," Australian Journal of Botany, vol. 62, no. 6, pp. 490-498, 2014.

[78] I. Garonna, R. de Jong, A. J. W. De Wit, C. A. Mücher, B. Schmid, and M. E. Schaepman, "Strong contribution of autumn phenology to changes in satellite-derived growing season length estimates across Europe (1982-2011)," Global Change Biology, vol. 20, no. 11, pp. 3457-3470, 2014.

[79] G. Fu, S.-W. Li, W. Sun, and Z.-X. Shen, "Relationships between vegetation carbon use efficiency and climatic factors on the Tibetan plateau," Canadian Journal of Remote Sensing, vol. 42, no. 1, pp. 16-26, 2016.

[80] J. Tao, Y. J. Zhang, J. T. Zhu et al., "Elevation-dependent temperature change in the Qinghai-Xizang plateau grassland during the past decade," Theoretical and Applied Climatology, vol. 117, no. 1-2, pp. 61-71, 2014.

[81] D. Lu, X. Xu, H. Tian, E. Moran, M. Zhao, and S. Running, "The effects of urbanization on net primary productivity in southeastern China," Environmental Management, vol. 46, no. 3, pp. 404-410, 2010.

[82] A. Buyantuyev and J. Wu, "Urbanization alters spatiotemporal patterns of ecosystem primary production: a case study of the Phoenix metropolitan region, USA," Journal of Arid Environments, vol. 73, no. 4-5, pp. 512-520, 2009.

[83] A. L. Liu, W. H. Kuang, F. Y. Ding, H. M. Yan, and T. R. Yang, "Impacts of urban and industrial land expansion on net primary productivity of China during 2000-2015," Arid Land Geography, vol. 40, no. 4, pp. 805-816, 2017. 